\title{
Basophils in Tuberculin and "Jones-Mote" Delayed Reactions of Humans
}

\author{
Philip W. Askenase and J. Edward Atwood \\ From the Department of Medicine, Yale University School of Medicine, New Haven, \\ Connecticut 06510
}

A B S T R A C T Jones-Mote reactions are delayed, erythematous, and mildly indurated cutaneous reactions originally described in humans sensitized by skin injection of heterologous proteins. Similar reactions in guinea pigs contain many basophils and are called cutaneous basophil hypersensitivity. In contrast, guinea pigs immunized with mycobacterial adjuvants have classical tuberculin-type delayed hypersensitivity reactions, which contain few basophils. This has led to a new classification of delayed responses, based largely on the presence or absence of basophils. We induced sensitization for JonesMote reactions in 20 normal humans by intradermal injections of keyhole limpet hemocyanin. Skin tests with KLH 1 wk later showed erythematous and indurated delayed reactions in all subjects. Rebuck skin windows showed specific accumulations of basophils with a delayed time-course in 18 of 20 subjects. In 12 normals sensitized with oxazolone-keyhole limpet hemocyanin conjugates, skin reactions and in vitro lymphocyte stimulation showed carrier and not hapten specificity, suggesting that cutaneous responses were probably mediated by T cells.

A comparative study of strongly positive PPD skin tests in patients with tuberculosis showed significant basophil accumulations in five of nine subjects. Thus, basophils occurred in human tuberculin and Jones-Mote reactions and were not a distinguishing feature of Jones-Mote reactions. We suggest that the occurrence of basophils at delayed reactions is under complex regulation and that basophil accumulations are an aspect of delayed hypersensitivity, rather than an indication of a distinctive and separate response.

Dr. Askenase is the recipient of Allergic Diseases Academic Award AI-70829, and Dr. Atwood was the recipient of a student fellowship from the Syntex Corporation.

Received for publication 5 February 1976 and in revised form 26 July 1976.

\section{INTRODUCTION}

Delayed cutaneous responses to intradermal skin tests are often employed to assess immune competence. Clinical tuberculin reactions, and delayed hypersensitivity reactions of animals immunized with adjuvants containing mycobacteria (i.e., complete Freund's adjuvant) are the prototypes of cell-mediated immune reactivity. However, humans can also be sensitized for delayed-type reactions without concurrent exposure to mycobacteria by intradermal injection of heterologous proteins. Compared to tuberculin reactions, the delayed responses induced by mere injection of proteins alone are less intense, less prolonged after testing, and more evanescent after sensitization (1). These weaker and more ephemeral delayed-type responses are often called Jones-Mote reactions $(2,3)$.

Similar delayed reactions can be obtained in guinea pigs by immunization without mycobacterial adjuvants. These responses have recently been examined with specialized histological techniques, and have been shown to contain large basophil infiltrates previously not appreciated $(4,5)$. Basophilic delayed reactions are called cutaneous basophil hypersensitivity (CBH), ${ }^{1}$ and numerous basophils have been found in a variety of delayed reactions of guinea pigs, humans, and other species (6). The discovery that some but not all delayed cutaneous hypersensitivity reactions contain large basophil infiltrates has led to a new classification of these responses based largely on the presence or absence of basophils.

Earlier studies of the cellular composition of clini-

\footnotetext{
${ }^{1}$ Abbreviations used in this paper: CFA, complete Freund's adjuvant; CBH, cutaneous basophil hypersensitivity; KLH, keyhole limpet hemocyanin; PBS, phosphate buffered saline; Ox-KLH, oxazolone-KLH; PPD, purified protein derivative of tuberculin; $\mathrm{DH}$, delayed tuberculintype hypersensitivity.
} 


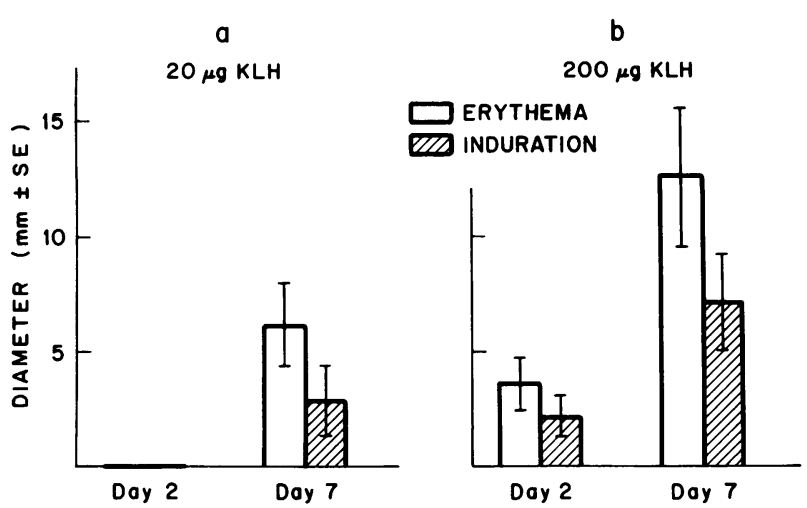

Figure 1 Macroscopic delayed cutaneous flare reactions to KLH. 20 normal nonimmune subjects were injected intradermally with 20 and $200 \mu \mathrm{g} \mathrm{KLH}$ and the macroscopic erythema and induration at these skin sites of primary immunization was noted $48 \mathrm{~h}$ and 7 days later.

cal delayed responses were performed by Rebuck and Wolf-Jergensen, who employed the simple skin window technique $(7,8)$. Basophils were noted at various human delayed-type reactions, but Jones-Mote type reactions were not examined and thus prompted the present study of these reactions by the skin window technique. We found that intradermal injection of the protein antigen keyhole limpet hemocyanin (KLH) could sensitize normal humans for delayed cutaneous responses resembling Jones-Mote reactions. Accumulation of basophils with a delayed time-course characterized these reactions and was a sign of specific sensitization. Tuberculin reactions, which differed in some respects from human JonesMote reactions, nevertheless were also often accompanied by significant basophil responses.

\section{METHODS}

Subjects. 25 normal volunteers of both sexes, 25-30 yr old and 9 male patients convalescing from documented pulmonary tuberculosis at the West Haven Veterans Administration Hospital, New Haven, were studied. An experimental summary was provided, along with the informed consent form approved by the Committee on Human Experimentation at Yale-New Haven Hospital.

Antigens. Normal subjects were tested intradermally with the protein antigen $\mathrm{KLH}$, obtained as an $\mathrm{NH}_{4} \mathrm{SO}_{4}$ precipitate from Pacific Bio-Marine Supply Co., Venice, Calif., solubilized by dialysis against $10 \mathrm{mM}$ Tris-buffered (pH 8.0) saline $(0.15 \mathrm{M})$ and stored in sterile vials in 10 $\mathrm{mM}$ phosphate-buffered saline ( $\mathrm{pH}$ 7.4) after debris was removed by centrifugation and Millipore filtration (Millipore Corp., Bedford, Mass.). The preparation of oxazolone (2-phenyl-4-ethoxy methylene-5-oxazolone (Ox)-KLH and Ox-human serum albumin (HSA) has been previously described $(9,10)$. Patients were skin tested with intermediate strength purified protein derivative (PPD, Connaught Laboratories, Ltd., Willowdale, Toronto, Canada) containing 5 tuberculin $U$ or $0.1 \mu \mathrm{g}$ of protein.

Sensitization of normal subjects for Jones-Mote reac- tions by intradermal injections of $K L H$. Four intradermal injections were performed on the volar surface of one forearm on day 0 . The first and most distal injection was a "minimal wheal" (about $0.01 \mathrm{ml}$ ) containing about $2 \mu \mathrm{g}$ $\mathrm{KLH}$ to test for immediate hypersensitivity. If no wheal and flare reaction was noted within $20 \mathrm{~min}$, two skin sites received $0.1 \mathrm{ml}$ intradermal injections of $20 \mu \mathrm{g} \mathrm{KLH}$, one to be observed macroscopically and the other for a skin window (see below). The fourth and most proximal $0.1-\mathrm{ml}$ injection contained $200 \mu \mathrm{g} \mathrm{KLH}$, or $90 \%$ of the total sensitizing dose of $222 \mu \mathrm{g}$. This protocol sequentially allowed: $(a)$ identification of rare individuals who might have anaphylactic reactions; $(b)$ use of each person as his own control for subsequent macroscopic and microscopic delayed skin testing; and $(c)$ immunization.

At day 7, skin testing with KLH was repeated on the contralateral forearm without the $200 \mu \mathrm{g}$ dose, and again on days 14 and 21 without the skin window. No immediate wheal and flare reactions were elicited with KLH at day 0 or day 7 . The tuberculosis patients received two simultaneous PPD tests: on one forearm the macroscopic reactions were followed, and on the other forearm PPD was injected into the abrasion of a skin window. Skin tests with KLH and PPD were observed for macroscopic reactions at $6,12,24,48$, and $72 \mathrm{~h}$. Erythema and induration were sequentially recorded by measuring perpendicular axial and sagittal diameters of redness and hardness, respectively. The results were expressed as an average of these two diameters in millimeters. The intensity of erythema and induration was graded $0-4^{+}$.

Microscopic studies of skin reactions. The skin window technique, originally described by Rebuck, was employed (7). The volar surface of the forearm was cleansed with $70 \%$ isopropyl alcohol, after which a sterile Bard Parker, No. 22 scalpel blade (Becton-Dickinson \& Co., East Rutherford, N. J.) was used to gently scrape off a $0.5-\mathrm{cm}^{2}$ area of epidermis down to the capillaries of the uppermost dermis, which appeared as fine bleeding points. Then $20 \mu \mathrm{g} \mathrm{KLH}$ or $0.1 \mu \mathrm{g}$ PPD was injected intradermally just beneath the surface of the abraded area. A sterile, precleansed $15-\mathrm{mm}^{2}$ glass cover slip (Arthur II. Thomas Co., Philadelphia, Pa.) was placed on this area, covered with a sterile cardboard square and Micropore tape (3M Co., St. Paul, Minn.), and changed at $6,12,24,36$, and $48 \mathrm{~h}$. The cover slips were air-dried and Wright's-stained. As a control on possible variations in staining from day to day, a stored peripheral blood smear known to contain basophils was also stained.

Slides were viewed under oil power objective $(1,000 \mathrm{X})$ and cells were counted by a "fixed method" (11) in which a predetermined and fixed coordinate system was used to determine whether a cell was included in the differential. Usually 200-400 cells were counted per cover slip, but when only a few hundred cells were present, all cells on the entire coverslip were counted. A total of 146 cover slips from reactions in 29 individuals were counted. Leukocytes were divided into four morphologic types: basophils, eosinophils, mononuclear cells, and polymorphonuclear neutrophils. Basophils were characterized by deep purple granules of various sizes filling the cytoplasm and often obscuring the nucleus (Fig. 6). Only basophils comprised of a cytoplasmic membrane, granules, and an intact nucleus were counted. The minimal number of purple to black granules necessary to identify a basophil was arbitrarily set at five; however, most basophils had at least 20 or more granules. Eosinophils had distinctive orangered granules of constant size that filled the cytoplasm and often obscured a bilobate nucleus. Polymorphonuclear 
neutrophils had multisegmented nuclei and clear, pale pink cytoplasm. The cells classified as mononuclear cells were nongranulocytic cells, such as lymphocytes, monocytes, and macrophages (Figs. 6, $8 a$ and $b$ ). These cells usually had a clear, slightly blue-gray to colorless cytoplasm surrounding a nonsegmented nucleus. The size of the mononuclear cells varied greatly and some appeared to have phagocytized granules. Occasionally, particularly in PPD skin windows at 24-48 h, the granules in the cytoplasm of mononuclear cells appeared very similar to the granules of basophils.

Blood collection and in vitro studies. Before skin testing, blood was collected from some subjects, selected at random, for in vitro lymphocyte culture in quadruplicate wells of microtrays, by a previously described method (12). A stored autologous serum pool from a set group of three unimmunized normal persons was used to support the cell cultures. This avoided the potential modulation of blastogenesis by $\mathrm{KLH}$ antibody that might be contained in autologous sera or by factors in individual homologous sera (13). Stimulation of DNA synthesis by $K L H, O x-K L H$, or Ox-HSA $(20-100 \mu \mathrm{g} / \mathrm{ml})$ was measured by the incorporation of ${ }^{3} \mathrm{H}$-labeled thymidine added to the cells at day $7.4 \mathrm{hr}$ later, the cells were collected on an automatic sample harvester and processed for scintillation counting. Results of KLH-induced lymphocyte proliferation were expressed solely as the stimulation index (counts per minute with $\mathrm{KLH} /$ counts per minute of cells cultured in medium alone) because the background incorporation of thymidine was equivalent (and low) in these normal volunteers (14).

Statistics. $P$ values were determined by using Student's $t$ test for paired data for comparisons between macroscopic diameters of KLH reactions of normal individuals at various times, and the Wilcoxon matched pairs signed-ranks test for comparisons of the percentage of basophils. For the PPD reactions, an unpaired $t$ test was employed and the MannWhitney $U$ test was used for the percentage of basophils. $P<0.05$ was taken as a significant difference.

\section{RESULTS}

"Delayed flare reactions" to KLH. Many normal subjects had macroscopic delayed flare reactions on days 5-8 at the original intradermal sites used for KLH sensitization (Fig. 1). Flare reactions at the 20$\mu \mathrm{g}$ site of day 0 were noted at day 7 in $40 \%$ of normal subjects (8 of 20). No subject had any visible reaction 24,48 , or $72 \mathrm{~h}$ after the initial $20 \mu \mathrm{g}$ $\mathrm{KLH}$ injection of day 0 (Fig. $1 a$ ), and half showed slight 24 and $48-\mathrm{h}$ reactions at the $200 \mu \mathrm{g} \mathrm{KLH}$ injection site of day 0 (Fig. $1 b$ ). These reactions, which may have represented irritation, subsequently disappeared and flare responses appeared at these sites on day 5 or 6 . By day 7 (before repeat skin testing to detect specific sensitization), these delayed flare reactions were significantly greater in erythema and induration than the minimal reactions at the site of this original $200 \mu \mathrm{gLH}$ injection at 24 and $48 \mathrm{~h}$ (Fig. 1b). It was concluded that intracutaneous injection of $\mathrm{KLH}$ was sufficient to sensitize humans for delayed reactions, and that enough of this antigen may have been retained at the location of the original skin test to result in a flare at this primary site.

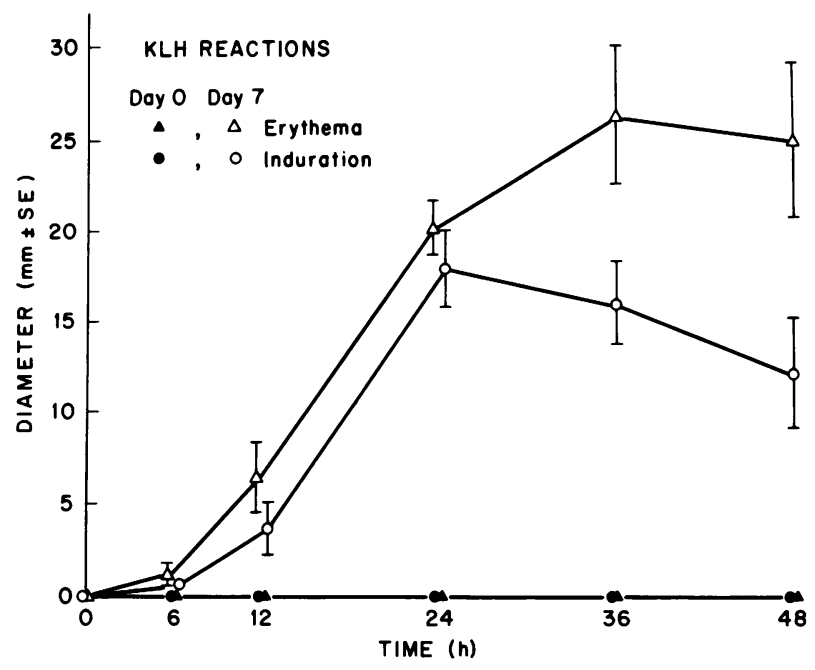

Figure 2 Delayed cutaneous reactions at day 0 (closed symbols) and at day 7 (open symbols), after intradermal skin test injection of $20 \mu \mathrm{g} \mathrm{KLH}$ in 20 normal volunteers.

Macroscopic "delayed-type reactions" to KLH. Reactions to the $20 \mu \mathrm{g} \mathrm{KLH}$ skin test of day 7 were delayed in onset (first detectable at $12 \mathrm{~h}$ ) and prolonged in maximal intensity over 24-72 h (Fig. 2). Most reactions were only moderately erythematous $\left(2^{+}\right)$. Some were more pronounced $\left(3^{+}\right)$, but none were intensely red and hemorrhagic $\left(4^{+}\right)$. All delayed reactions to $\mathrm{KLH}$ had a definitely harder, raised area (induration), which on a scale from $0-4^{+}$(almost rockhard) was never greater than $3^{+}$. Reactions were uniformly warm and pruritic. The diameters of erythema and induration were identical at $24 \mathrm{~h}$, but thereafter induration remained constant over 36 and $48 \mathrm{~h}$ while erythema rose (Fig. 2).

Experiments were performed to test the hapten vs. carrier specificity of these reactions. Normal subjects were sensitized by intradermal injection with an $\mathrm{Ox}-\mathrm{KLH}$ conjugate, and 1 wk later skin tests were repeated with Ox-KLH, KLH, and Ox-HSA. Delayed reactions were elicited only with the immunizing conjugate or the carrier (KLH), and not with oxazolone (the immunizing hapten) conjugated with another carrier (HSA), even in high dosage (Table I). It was concluded that delayed cutaneous responses, achieved by intradermal sensitization with Ox-KLH, were carrier and not hapten specific.

Skin reactions resulting from weekly testing with $K L H$. There were no immediate wheal and flare reactions at day $7 \mathrm{KLH}$ skin tests. However, when skin testing was repeated at weekly intervals, a reproducible phenomenon developed, which consisted of the onset of immediate reactions, and parallel depression of fully developed delayed reactions. Immediate reactions were erythematous, edematous, 
TABLE I

Skin Reactions and Lymphocyte Stimulation in Human Volunteers Sensitized with $\mathrm{Ox}-\mathrm{KLH}$

\begin{tabular}{lcccc}
\hline & $\begin{array}{c}\text { No. } \\
\text { individuals }\end{array}$ & $\begin{array}{c}\text { Ox-KLH } \\
20 \mu \mathrm{g}\end{array}$ & $\begin{array}{c}\text { KLH } \\
20 \mu \mathrm{g}\end{array}$ & $\begin{array}{c}\text { Ox-HSA } \\
200 \mu \mathrm{g}\end{array}$ \\
\hline $\begin{array}{c}\text { 24-h skin re- } \\
\text { action, } m m\end{array}$ & 12 & $13.6 \pm 1.5$ & $15.8 \pm 1.2$ & 0 \\
$\begin{array}{c}\text { induration } \\
\text { Lymphocyte } \\
\text { stimulation } \\
\text { index }\end{array}$ & 5 & $9.5 \pm 2.3$ & $5.9 \pm 1.2$ & $2.1 \pm 0.34$ \\
\hline
\end{tabular}

Subjects were sensitized with three or four intradermal injections containing a total of $200-400 \mu \mathrm{g} \mathrm{Ox}-\mathrm{KLH}$ on day $0.1 \mathrm{wk}$ later blood was drawn for in vitro studies, and skin tests were then repeated. The skin test doses were injected in $0.1 \mathrm{ml}$, and the in vitro stimulation doses refer to the protein concentration per milliliter. Results are $\pm \mathrm{SE}$.

pruritic, and warmer than the surrounding skin; and disappeared within 30-60 min. Concomitant delayed reactions of days 14 and 21 were similar to day 7 reactions, but were of shorter duration. Fig. 3 shows that 48-h erythema and induration progressively and significantly declined as immediate wheal and flare reactions progressively and significantly increased.

Delayed reactions to intermediate-strength PPD. All nine tuberculosis patients tested with PPD had delayed reactions beginning at $6 \mathrm{~h}$ and reaching a peak at 36-48 h (Fig. 4). In five of nine patients, there were severe reactions with a central area of $3^{+}-4^{+}$erythema and $3^{+}-4^{+}$induration of approximately $20 \mathrm{~mm}$ diameter, surrounded by a concentric ring of moderate induration and erythema. In contrast to delayed KLH reactions, erythema and indura- tion of PPD reactions were still present after $1 \mathrm{wk}$. Vesicles were noted at the reaction center in four of the five severe reactors. In contrast, only two of 20 $\mathrm{KLH}$ reactions had vesicles. Compared to the delayed reactions elicited by KLH, the PPD-induced delayed reactions (elicited by only $0.1 \mu \mathrm{g}$ protein) were more erythematous, more indurated, and more prolonged (Fig. 2 vs. Fig. 4).

Skin window microscopic studies of $K L H$ delayed reactions. Basophils were rarely found on control windows of day 0 , and were uniformly and significantly present in skin windows of delayed reactions on day 7 (Fig. $5 a$ ). These cells had the appearance of basophils in peripheral blood (Fig. 6). At $36 \mathrm{~h}$, many individuals had $9-12 \%$ basophils, and the mean percentage of basophils was highest (6.6\%).

Eosinophils were infrequently found in control (day 0 ) or test (day 7) windows. However, in the day 7 set of windows, eosinophils showed a significant increase in the 36 -h reactions, where they were $1.5 \%$ of the cells. In both day 0 and day 7 sets of $\mathrm{KLH}$ windows, polymorphs followed similar trends of initial 6-h predominance that subsequently declined and was replaced by predominance of mononuclear cells in the 24-h windows (Fig. 7a). Thus, basophils and eosinophils were only present in 7-day, delayed reactions to $\mathrm{KLH}$, and not in day 0 control windows. The accumulation of these cells had a delayed timecourse, which paralleled the specific macroscopic reactions. One person who had a large flare reaction at the site of his original KLH tests of day 0 decided to discontinue the study at day 7 . However, he agreed to allow a skin window to be placed on this reaction about $24 \mathrm{~h}$ after it had begun, and $4 \mathrm{~h}$ later the window showed $73 \%$ mononuclear cells with sig-
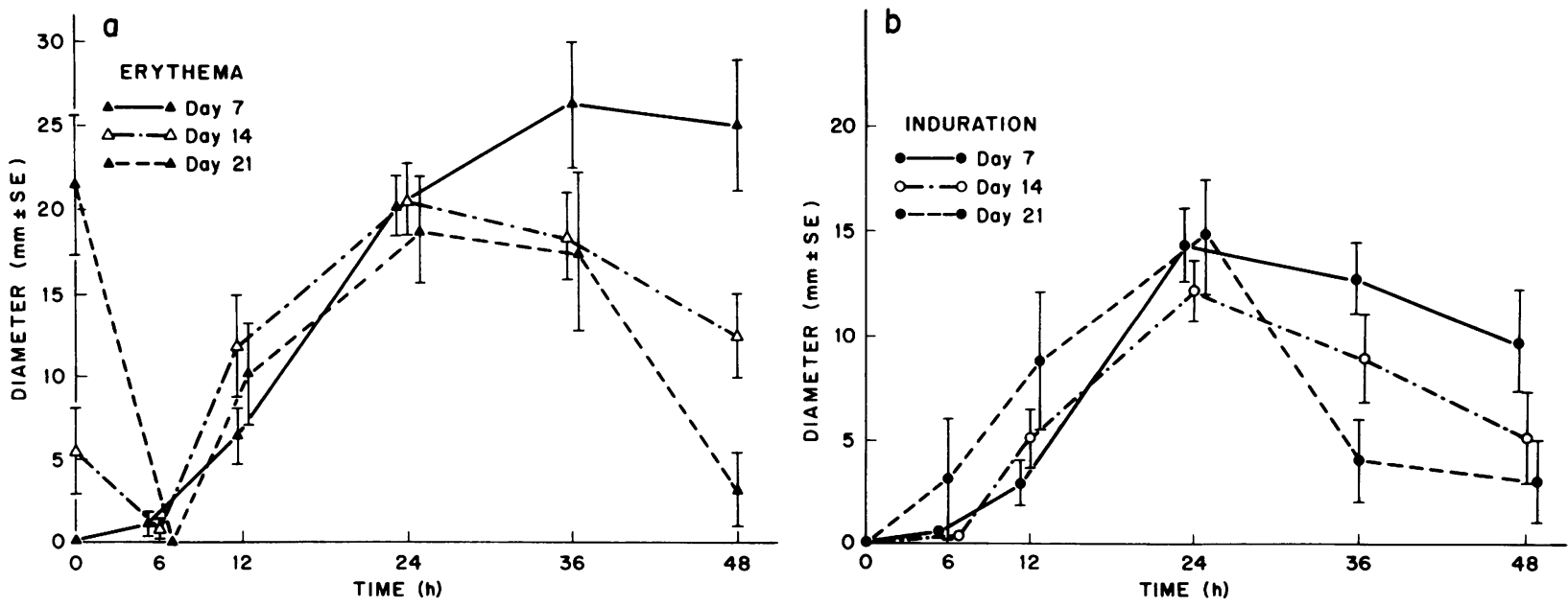

FIGURE 3 Cutaneous erythema $(a)$ and induration $(b)$ in 15 normal individuals sensitized with KLH on day 0 and skin-tested with $20 \mu \mathrm{g}$ KLH at days 7, 14, and 21. 


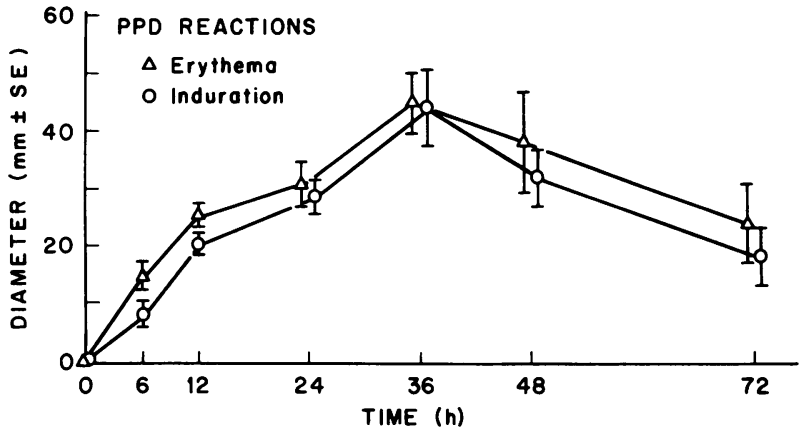

Figure 4 Delayed cutaneous responses to skin testing with $5 \mathrm{U}$ of tuberculin (PPD) in nine individuals with active pulmonary tuberculosis.

nificant basophils (6.5\% compared to $0.5 \%$ in the 24 -h control window of day 1) and many eosinophils (16\%).

Skin windows at PPD reactions. Basophils were also noted in skin windows at PPD reactions. The mean percentage of basophils in 24-48 h tuberculin reactions of all patients was constant at about $3 \%$. However, it was noted that basophils in PPD reactions varied in individual tuberculosis patients from 0 to $10 \%$. PPD reactions were clearly separable into two distinct groups; with and without basophils. Table II shows that basophils at $24-48 \mathrm{~h}$ varied between 3.7 and $10.0 \%$ in four of the nine PPD reactors, while the other five of nine had less than $2.0 \%$ basophils at all times. The higher percentage of basophils was observed in some patients with huge and very indurated macroscopic reactions, but similar florid reactions of other patients showed few baso- phils at any time. These two groups were also indistinguishable in clinical disease or treatment. The delayed onset and prolonged accumulation of basophils in nearly half of the PPD reactions (Fig. $5 b$ ) was quite similar to the basophils at day $7 \mathrm{KLH}$ reactions, while the low-basophil PPD reactions were similar to day $0 \mathrm{KLH}$ control tests (Fig. $5 a$ ).

Basophils in PPD reactions differed from those seen at KLH-induced delayed reactions in that they generally contained fewer granules per cell. This observation was not quantitated, but it seemed that basophils of PPD windows were less cluttered with granules, and the nucleus was more easily observed (Figs. $8 a$ and $8 b$ ). In addition, mononuclear cells containing granules that appeared to have originated in basophils were more common on PPD skin windows and in a greater percentage of subjects $(80 \%)$, in comparison to those found in the set of day $7 \mathrm{KLH}$ windows (22\%). The abrasion upon which the PPD skin window had been placed did not dry out as quickly as the abrasion at the KLH test; hence, more 48-h microscopic readings were possible at PPD reactions. Eosinophils appeared in greater numbers and peaked much earlier $(6 \mathrm{~h})$ in PPD reactions than in $\mathrm{KLH}$ reactions.

Polymorphs and mononuclear cells at PPD reactions (Fig. $7 b$ ) showed the same nonspecific patterns found in the day 0 and day $7 \mathrm{KLH}$ reactions (Fig. $7 a$ ). Thus, polymorphs were predominant in the 6-h PPD reactions, and this converted to a predominance of mononuclear cells in later windows. However, compared to day 0 and day $7 \mathrm{KLH}$ windows, mononuclear cells were not predominant in PPD reactions at $24 \mathrm{~h}(P<0.05)$, but predominated later a.

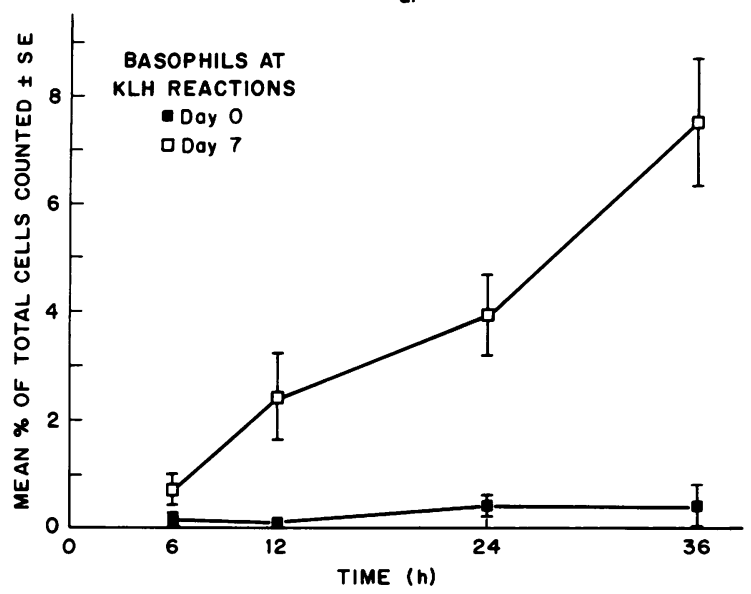

b.

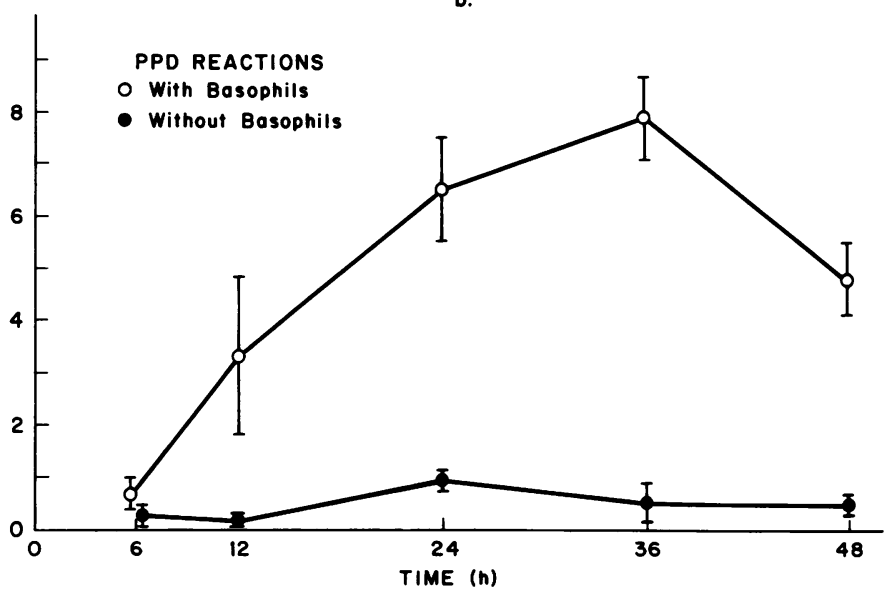

FIGURE 5 Skin window responses of basophils at KLH reactions (a) in 17 normal volunteers sensitized at day 0 with KLH and skin-tested at day 0 (closed symbols) and day 7 (open symbols) with $20 \mu \mathrm{g}$ KLH. $b$ shows skin window responses of basophils in 9 individuals with active pulmonary tuberculosis tested with PPD. Tuberculin reactions without basophils (closed symbols) had less than $2.0 \%$ basophils at all times. 


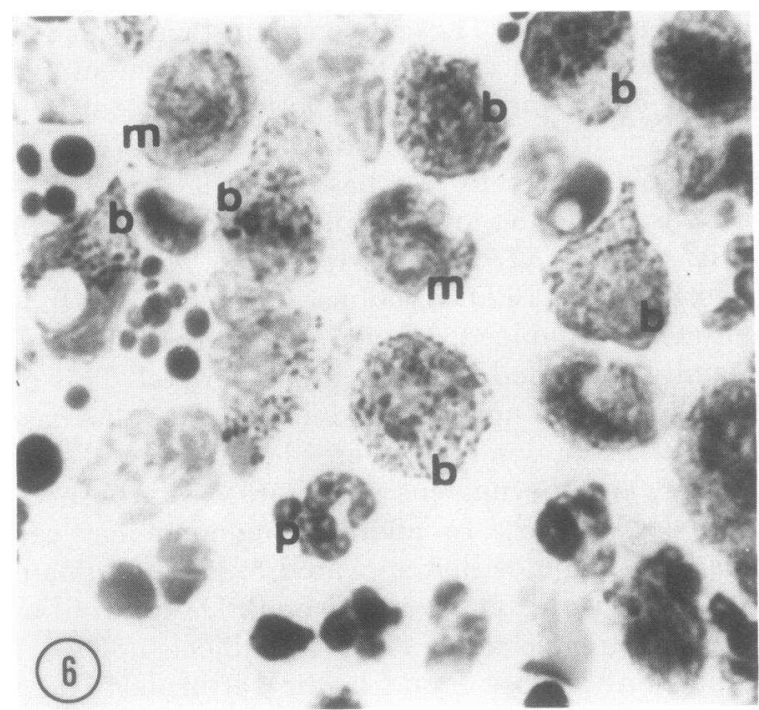

FIGURE 6 Skin window from a 36-h reaction elicited with $20 \mu \mathrm{g}$ KLH in a normal volunteer 7 days after immunization by intradermal injection of KLH. Numerous basophils (b) are seen. Their cytoplasm is packed with granules that obscure the nucleus. Polymorphonuclear neutrophils (p), and mononuclear cells (m) are the other cell types observed.

in the windows of 36 and 48-h PPD reactions (Fig. $7 a$ vs. $7 b$ ). Thus polymorphs lasted longer and mononuclear cells (as percentages of total cells) came on later at PPD reactions.

Lymphocyte stimulation studies in volunteers sensitized with KLH. Mononuclear cells obtained just before intradermal immunization and just before subsequent weekly skin testing were cultured in vitro with KLH. All subjects whose cells were cultured showed significant stimulation 1 wk after sensitization, and cells from individuals sensitized with $\mathrm{Ox}-\mathrm{KLH}$ were only stimulated with Ox-KLH or $\mathrm{KLH}$, and not with Ox-HSA, even in much higher doses (Table I), and even in aggregated form (data not shown). It was concluded that in vitro lymphocyte stimulation was carrier and not hapten specific. In subjects who had repeated weekly KLH skin tests, there was a trend toward increased lymphocyte stimulation with KLH on successive weeks (Fig. 9), which coincided with the progressively attenuated delayed reactions and increasing immediate reactions described above (Fig. $3 a$ and $3 b$ ).

\section{DISCUSSION}

We have immunized normal subjects with KLH and have reproduced delayed skin reactions first described in humans by Jones and Mote $(2,3)$. Our delayed reactions have been examined by Dr. John Mote (personal communication), who found these responses identical to the reactions he studied with Dr. T. Duckett Jones. They are macroscopically indistinguishable from clinical tuberculin reactions, except for the somewhat lesser intensity and less prolonged induration in the KLH reactions. However, a key distinction between these delayed reactions occurs in subsequent tests, which characteristically reveal the emergence of immediate wheal and flare reactions and concurrent decreased delayed reactions (Fig. $3 a$ and $b$ ). Similar evolution of reactivity was noted by Jones and Mote $(2,3)$ and others $(1,15)$. In addition, we have noted that a progressive rise in antigentriggered lymphocyte stimulation (Fig. 9) coincides with rising immediate reactions and falling
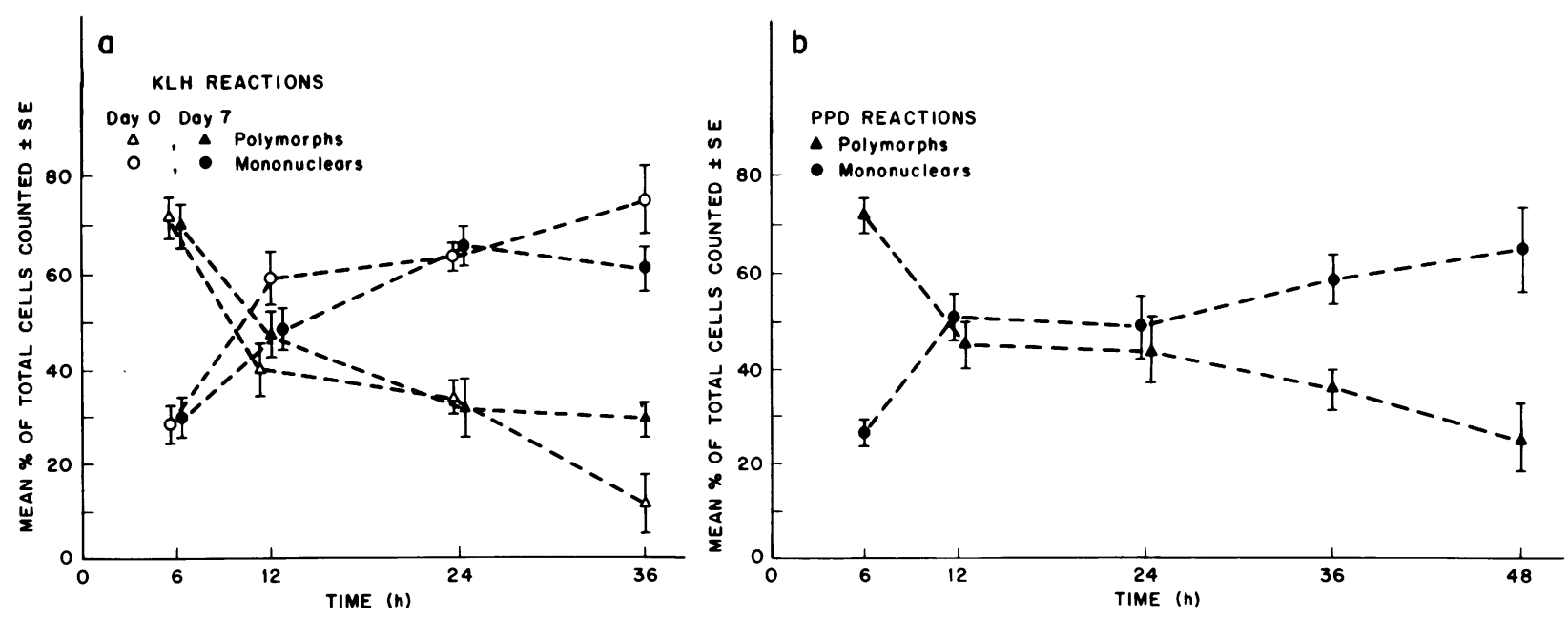

FIGURE 7 Neutrophil and mononuclear cell responses at skin windows over KLH skin tests at day 0 and day 7 in normal volunteers $(a)$, and at PPD skin tests in individuals with active pulmonary tuberculosis $(b)$. 


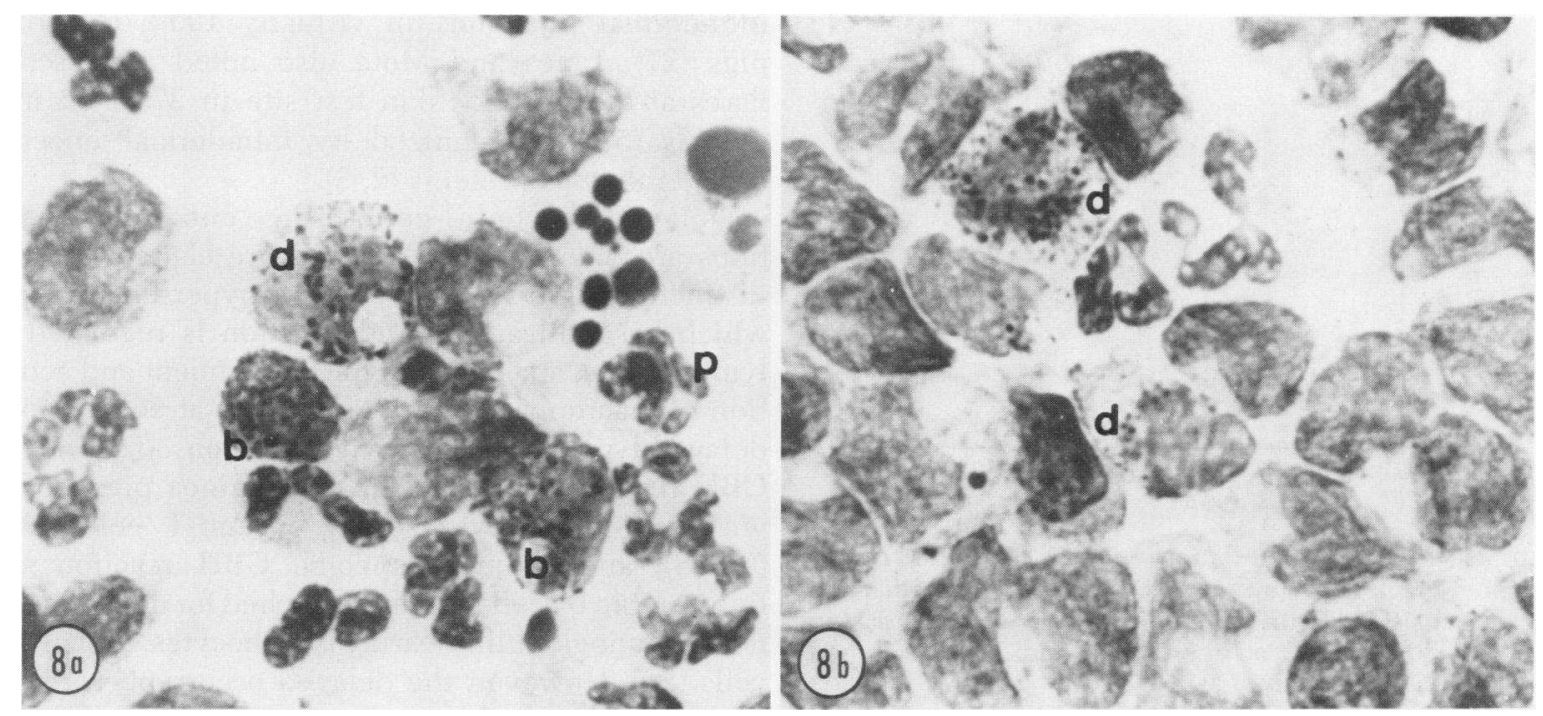

FIGURE 8 Skin windows from delayed reactions in patients with tuberculosis elicited by PPD at $24(a)$ and $48 \mathrm{~h}(b)$. In $(a)$ two basophils (b) are packed with granules. However, another basophil (d) in $a$ and the two noted in $(b)$ contain fewer granules, many of which are pale:staining, suggesting partial degranulation of basophils.

delayed reactions. It has been suggested that the duration of delayed reactions is normally regulated by an active shut-off process, which may be exaggerated in certain clinical conditions associated with anergy, such as sarcoidosis, mononucleosis, and Hodgkin's disease (16). The decline in the duration of KLH delayed reactions in successive weekly tests, amidst equivalent 24-h intensity and rising lymphocyte stimulation, is consistent with the progressive growth of such a normal active suppression. Since some of these anergic conditions have been associated with elevated IgE levels (17-19), one hypothesis to explain this association, and the findings of the current study, is that continuous or repetitive antigenic challenge stimulates a subpopulation of thymic-derived lymphocytes that suppresses delayed reactions and concurrently

TABLE II

Basophils in Skin Windows at Tuberculin Reactions

\begin{tabular}{cccccc}
\hline Patient & $6 \mathrm{~h}$ & $12 \mathrm{~h}$ & $24 \mathrm{~h}$ & $36 \mathrm{~h}$ & $48 \mathrm{~h}$ \\
\hline
\end{tabular}

basophils countedltotal cells counted $=\%$ basophils

PPD reactions with

basophils

$\begin{array}{ll}\text { HAR } & 0 / 201=0 \% \\ \text { SIW } & 3 / 200=1.5 \% \\ \text { OAK } & 1 / 223=0.5 \% \\ \text { BRU } & 3 / 400=0.8 \%\end{array}$

Mean $\% \pm \mathrm{SE}$

PPD reactions without* basophils

$\begin{array}{ll}\text { SHE } & 0 / 222=0 \% \\ \text { GIL } & 0 / 389=0 \% \\ \text { COV } & 0 / 200=0 \% \\ \text { BRO } & 1 / 280=0.4 \% \\ \text { ERI } & 3 / 375=0.8 \%\end{array}$

Mean\% $\% \mathrm{SE}$

$$
0.7 \pm 0.3
$$

$$
\begin{aligned}
10 / 416 & =2.4 \% \\
2 / 513 & =0.4 \% \\
15 / 202 & =7.5 \% \\
16 / 572 & =2.8 \%
\end{aligned}
$$

$$
3.3 \pm 1.5
$$

$$
\begin{aligned}
& 0 / 216=0 \% \\
& 0 / 203=0 \% \\
& 0 / 200=0 \% \\
& 2 / 268=0.7 \% \\
& 1 / 512=0.2 \%
\end{aligned}
$$

$$
0.2 \pm 0.2
$$

$$
\begin{aligned}
& 21 / 416=5.0 \% \\
& 21 / 223=9.4 \% \\
& 15 / 253=5.9 \% \\
& 23 / 402=5.5 \%
\end{aligned}
$$$$
6.5 \pm 1
$$

$$
\begin{aligned}
& 14 / 200=7.0 \% \\
& 20 / 306=6.5 \% \\
& 20 / 200=10.0 \% \\
& 16 / 200=8.0 \%
\end{aligned}
$$$$
10 / 200=5.0 \%
$$$$
9 / 244=3.7 \%
$$$$
13 / 200=6.5 \%
$$$$
8 / 200=4.0 \%
$$

$$
7.9 \pm 0.8
$$$$
4.8 \pm 0
$$

\footnotetext{
* Less than $2.0 \%$ basophils at all times.
} 


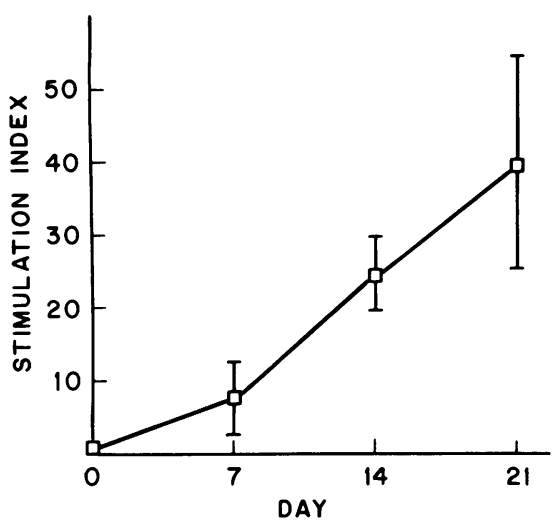

FIgURE 9 In vitro stimulation with KLH $(100 \mu \mathrm{g} / \mathrm{ml})$ of peripheral blood lymphocytes from seven normal individuals sensitized with $222 \mu \mathrm{g} \mathrm{KLH}$ at day 0 and skin tested with $20 \mu \mathrm{g} \mathrm{KLH}$ at days 7, 14, and 21, after blood drawing.

augments IgE responses. Further study will be necessary to examine this and other possible explanations for the inverse relationship between immediate and delayed hypersensitivity that we have noted.

Sensitization with the protein antigen $\mathrm{KLH}$ is in current wide use to assess the capacity of patients to mount a primary immune response (20-23), and to evaluate the ability to express a delayed-type hypersensitivity reaction (24). The findings of the current study have relevance to studies employing $\mathrm{KLH}$ as a rarely encountered antigen for determining whether transfer factor passively confers sensitivity or augments a preexisting state of latent immunity (25). We have found that basophils with a delayed timecourse characterize the delayed response that follows immunization of normal humans with KLH. Although elaborate histological techniques can be used to assess quantitatively the number of basophils at human delayed-type reactions (26), we feel that the simplicity and noninvasiveness of the skin window technique, as well as the ability to make multiple determinations at a single skin test site, recommend the clinical use of this technique. The addition of microscopic determination of basophils extends the ability to quantitate objectively the response to a given dose of transfer factor. However, our findings of sensitization by skin testing, and the modulation of delayed responses by multiple skin tests, severely limit the number of skin test evaluations for which transfer factor therapy can be used. The ability of skin testing to sensitize is underscored by the delayed flare reactions at the original site of intracutaneous KLH injections used for sensitization (Fig. 1). Although skin window examination was performed in only one individual, we have noted similar cutaneous basophil flare reactions to be induced by KLH intradermal injections in virtually $100 \%$ of guinea pigs (27). Jones and Mote also noted macroscopic flares at the primary skin test site in 27 of 52 individuals $(53 \%)$ immunized by intradermal injection of heterologous proteins $(2,3)$.

Delayed basophil-containing cutaneous reactions are often called CBH and are claimed to be a distinctive form of delayed-type hypersensitivity in which basophil arrival and function is regulated by lymphocytes, analogous to the recruitment and activation of macrophages by lymphocytes at conventional delayed-type hypersensitivity reactions (6). Indeed, $\mathrm{CBH}$ responses are inhibited in guinea pigs treated with anti-lymphocyte serum or anti-T cell serum $(6,28)$, and conjugate-specific $\mathrm{CBH}$ reactions are transferable by cell fractions enriched for nonadherent, nonimmunoglobulin-bearing lymphocytes, probably $\mathrm{T}$ cells (29). However, the delayed occurrence of basophils at cutaneous hypersensitivity reactions does not necessarily mean that these responses are mediated by $\mathrm{T}$ cells, as quite similar reactions are also transferable by small amounts of immune serum factors, which appear to be antibodies. In guinea pigs, $7 \mathrm{~S}$ IgG $_{1}$ anaphylactic-type antibodies seem responsible for these hapten-specific basophil responses $(5,9$, 30 ), and analogous "late" cutaneous reactions containing basophil accumulations are mediated by reaginic IgE antibodies in humans (31). Thus, antibody products of $\mathrm{B}$ cells and $\mathrm{T}$ cells can govern the arrival of these cells at delayed responses, and basophil arrival may be governed by complex regulatory factors that augment or suppress basophil infiltrates $(29,32-34)$.

In this study, antigen-induced lymphocyte stimulation and delayed cutaneous responses were carrier and not hapten specific in volunteers sensitized with $\mathrm{Ox}-\mathrm{KLH}$. This argues in favor of $\mathrm{T}$ cell rather than antibody mediation of the delayed basophil reactions. The $\mathrm{T}$ cell-dependence of in vitro lymphocyte stimulation in man has now been established (35), and cutaneous responses to the immunizing conjugate or to the carrier and not to the hapten are usually mediated by $T$ cells. It is highly unlikely that antibodies mediate the delayed accumulations of basophils we have noted in 7-day KLHinduced Jones-Mote reactions. Human "late" cutaneous hypersensitivity reactions, mediated by IgE antibodies (31), peak at $6-12 \mathrm{~h}$, are nearly gone by $24 \mathrm{~h}$, always follow strong wheal and flare responses, and should be hapten specific (36). Further study will be necessary to determine the histology, specificity, and mechanism underlying the complex dual cutaneous responses we have noted on repeat $\mathrm{KLH}$ skin testing.

Several observations in the current study suggest release of mediators by basophils at delayed reactions 
of humans. Many basophils had reduced numbers and staining of granules, and basophil-like granules were noted in mononuclear cells which had phagocytosed extruded basophil granules. These changes were particularly evident at PPD reactions, where macroscopic vesicle formation was a surprising and frequent occurrence, and the wetness of these reactions permitted many more 48 -h skin window determinations. In KLH delayed reactions, which generally contained more basophils, there was less degranulation and also less vesicle formation. Dvorak et al. have suggested a slow "piecemeal" degranulation of basophils at delayed reactions $(37,38)$, while we have shown that more total anaphylactic-type degranulation (which features immediate release of histamine, increased vasopermeability, and exocytosis of granules) can be induced in basophils that have arrived at delayed reactions (39). Electron microscopic study will be necessary to demonstrate definitely whether basophil degranulation occurs at human tuberculin and Jones-Mote reactions.

Delayed accumulations of basophils were noted in 18 of $20 \mathrm{KLH}$ reactions, and only 4 of $9 \mathrm{PPD}$ reactions. However, there was great overlap in percent basophils among PPD or KLH-sensitive individuals showing basophil accumulations. Others have noted significant basophils in clinical tuberculin reactions $(26,40)$. Thus, the occurrence of basophils is not a distinguishing feature of human Jones-Mote reactions. Basophils are generally not present in delayed-type hypersensitivity reactions of guinea pigs immunized with mycobacteria, and are said to be characteristic of Jones-Mote-type reactions in these animals $(4,6)$. However, several notable exceptions exist $(37,41)$, and basophils are not present in delayed hypersensitivity reactions of guinea pigs because of an apparent suppression. Transfer of putative $T$ cells from animals with classical delayed hypersensitivity reactions which lack basophils result in delayed reactions of recipients that are rich in basophils (29). These findings suggest that the arrival of basophils at delayed reactions is under complex regulation $(5,29,32-34)$. This could explain our finding of greatly varying numbers of basophils in seemingly similar tuberculin responses. We conclude that basophils are an aspect of delayed hypersensitivity reactions, rather than an indication of a distinctive and homogeneous separate reaction.

\section{ACKNOWLEDGMENTS}

The authors are indebted to Miss Mary Beth Kurpiewski for her secretarial skills and to Dr. Gerald Beck of the Biometry Branch of the Yale School of Epidemiology and Public Health for his assistance with statistical analysis of the data.

This work was supported in part by grants AI-12211 and AI-11077 from the National Institutes of Health, U. S. Public Health Service, and by grant IM-70B from the American Cancer Society.

\section{REFERENCES}

1. Brandriss, M. W., and W. E. Bullock, Jr. 1970. Human immunologic response to soluble antigens. I. Hypersensitivity induced by a hapten-altered native protein. J. Immunol. 105: 1416-1426.

2. Jones, T. D., and J. R. Mote. 1934. The phases of foreign protein sensitization in human beings. New Engl. J. Med. 210: 120-123.

3. Mote, J. R., and T. D. Jones. 1936. The development of foreign protein sensitization in human beings. J. Immunol. 30: 149-167.

4. Dvorak, H. F., A. M. Dvorak, B. A. Simpson, H. B. Richerson, S. Leskowitz, and M. J. Karnovsky. 1970. Cutaneous basophil hypersensitivity. II. A light and electron microscopic description. J. Exp. Med. 132: 558-582.

5. Askenase, P. W., J. D. Haynes, and B. J. Hayden. 1976. Antibody-mediated basophil accumulations in cutaneous hypersensitivity reactions of guinea pigs. J. Immunol. 117: 1722-1730.

6. Dvorak, H. F., and A. A. Dvorak. 1974. Cutaneous basophil hypersensitivity. In Progress in Immunology. II, L. Brent, and E. J. Holborow, editors. Vol. 3, Noord-Hollandsche Uitg. Mij., Amsterdam.

7. Rebuck, J. W. 1958. Technique for the study of leukocytic functions in man. Methods Med. Res. 7: 161-164.

8. Wolf-Jurgensen, P. 1966. Basophilic Leukocytes in Delayed Hypersensitivity. Munksgaard, A/S, Copenhagen.

9. Askenase, P. W. 1973. Cutaneous basophil hypersensitivity in contact-sensitized guinea pigs. I. Transfer with immune sera. J. Exp. Med. 138: 1144-1155.

10. Askenase, P. W., and G. L. Asherson. 1972. Contact sensitivity to oxazolone in the mouse. VIII. Demonstration of several classes of antibody in the sera of contact sensitized and unimmunized mice by a simplified antiglobulin assay. Immunology. 23: 289-298.

11. Garrie, S. A., and P. Wolf-Jurgensen. 1972. Comparison of methods of counting skin window coverslips. A statistical analysis. J. Allergy Clin. Immunol. 49: 238-244.

12. Munyer, T. P., R. J. Mangi, T. Dolan, and F. S. Kantor. 1975. Depressed lymphocyte function after measlesmumps-rubella vaccination. J. Infect. Dis. 132: 7578.

13. Mangi, R. J., J. M. Dwyer, and F. S. Kantor. 1974. The effect of plasma upon lymphocyte response in vitro. Demonstration of a humoral inhibitor in patients with sarcoidosis. Clin. Exp. Immunol. 18: 519-528.

14. Horowitz, D. A., P. Stastny, and M. Ziff. 1970. Circulating deoxyribonucleic acid-synthesizing mononuclear leukocytes. I. Increased numbers of proliferating mononuclear leukocytes in inflammatory disease. J. Lab. Clin. Med. 76: 391-402.

15. Simon, F. A., and F. M. Rackemann. 1934. The development of hypersensitiveness in man. I. Following intradermal injection of the antigen. J. Allergy. 5: 439450.

16. Kantor, F. S. 1975. Infection, anergy and cell-mediated immunity. N. Engl. J. Med. 292: 629-634.

17. Nordbring, F., S. G. O. Johansson, and A. Apsmark. 
1972. Raised serum levels of IgE in infectious mononucleosis. Scand. J. Intect. Dis. 4: 119-124.

18. Bergmann, K. C., I. Zaumseil, and B. Lachmann. 1973. Quantitative IgE-Bestimmung bei Sarkoidose. Z. Erkr. Atmungsorgane. 137: 351-352.

19. Waldmann, T. A., J. M. Bull, R. M. Bruce, S. Broder, M. C. Jost, S. T. Balestra, and M. E. Suer. 1974. Serum immunoglobulin $\mathrm{E}$ levels in patients with neoplastic disease. J. Immunol. 113: 379-386.

20. Swanson, M. A., and R. S. Schwartz. 1967. Immunosuppressive therapy. The relation between clinical response and immunologic competence. N. Engl. J. Med. 277: 163-170.

21. Curtis, J. E., E. M. Hersh, J. E. Harris, C. McBride, and E. J. Freireich. 1970. The human primary immune response to keyhole limpet haemocyanin: interrelationships of delayed hypersensitivity, antibody response and in vitro blast transformation. Clin. Exp. Immunol. 6: 473-491.

22. Horwitz, D. A. 1972. Impaired delayed hypersensitivity in systemic lupus erythematosus. Arthritis Rheum. 15: 353-359.

23. Fox, R. A., F. J. Dudley, and S. Sherlock. 1973. The primary immune response to haemocyanin in patients with primary biliary cirrhosis. Clin. Exp. Immunol. 14: 473-480.

24. Curtis, J. E., and E. M. Hersh. 1973. Cellular immunity in man: correlation of leukocyte migration inhibition factor formation and delayed hypersensitivity. Cell. Immunol. 8: 55-61.

25. Zuckerman, K. S., J. A. Neidhart, S. P. Balcerzak, and A. F. LoBuglio. 1974. Immunologic specificity of transfer factor. J. Clin. Invest. 54: 997-1000.

26. Dvorak, H. F., M. C. Mihm, Jr., A. M. Dvorak, R. A. Johnson, E. J. Manseau, E. Morgan, and R. B. Colvin. 1974. Morphology of delayed type hypersensitivity reactions in man. I. Quantitative description of the inflammatory response. Lab. Invest. 31: 111-130.

27. Askenase, P. W., J. D. Haynes, D. Tauben, and R. De Bernardo. 1975. Specific basophil hypersensitivity induced by skin testing and transferred using immune serum. Nature (Lond.). 256: 52-54.

28. Stadecker, M. J., and S. Leskowitz. 1976. The inhibition of cutaneous basophil hypersensitivity reactions by a heterologous anti-guinea pig $\mathrm{T}$ cell serum. $J$. Immunol. 116: 1646-1651.

29. Askenase, P. W. 1976. Cutaneous basophil hypersensitivity uncovered in the cell transfer of classical tuberculin hypersensitivity. J. Immunol. 117: 741-747.
30. Haynes, J. D., F. S. Kantor, and P. W. Askenase. 1975. Hapten specific cutaneous basophil hypersensitivity (CBH) transferred with small amounts of $7 \mathrm{~S}$ IgG $_{1}$ antibody. Fed. Proc. 34: 1039. (Abstr.).

31. Solley, G. O., G. J. Gleich, R. E. Jordon, and A. L. Schroeter. 1976. The late phase of the immediate wheal and flare skin reaction. Its dependence upon IgE antibodies. J. Clin. Invest. 58: 408-420.

32. Boetcher, D. A., and E. J. Leonard. 1973. Basophil chemotaxis:augmentation by a factor from stimulated lymphocyte cultures. Immunol. Commun. 2: 421-429.

33. Katz, S. I., C. J. Heather, D. Parker, and J. L. Turk. 1974. Basophilic leukocytes in delayed hypersensitivity reactions. J. Immunol. 113: 1073-1078.

34. Ward, P. A., H. F. Dvorak, S. Cohen, Y. Yoshida, R. Data, and S. S. Salvaggio. 1975. Chemotaxis of basophils by lymphocyte-dependent and lymphocyteindependent mechanisms. J. Immunol. 114: 15231531.

35. Chess, L., R. P. MacDermott, and S. F. Schlossman. 1974. Immunologic functions of isolated human lymphocyte subpopulations. II. Antigen triggering of T and B cells in vitro. J. Immunol. 113: 1122-1127.

36. Dolovich, J., F. E. Hargreave, R. Chalmers, K. J Shier, J. Gauldie and J. Bienenstock. 1973. Late cutaneous allergic response in isolated IgE-dependent reactions. J. Allergy Clin. Immunol. 52: 38-46.

37. Dvorak, H. F., A. M. Dvorak, and W. H. Churchill. 1973. Immunologic rejection of diethylnitrosamineinduced hepatomas in strain 2 guinea pigs. Participation of basophilic leukocytes and macrophage aggregates. J. Exp. Med. 137: 751-775.

38. Dvorak, A. M., M. C. Mihm, Jr., and H. F. Dvorak. 1976. Degranulation of basophilic leukocytes in allergic contact dermatitis reactions in man. J. Immunol. 116: 687-695.

39. Askenase, P. W., R. DeBernardo, M. Kashgarian, J. Douglas, and D. Tauben. 1976. Anaphylactic type basophil degranulation at delayed cutaneous basophil reactions. J. Allergy Clin. Immunol. 57: 193194. (Abstr.).

40. Wolf-Jurgensen, P. 1965. Basophilic leukocytes in experimental tuberculin reactions studied by the skinwindow technique. Acta. Allerg. 20: 38-46.

41. Dvorak, H. F., B. A. Simpson, R. C. Bast, Jr., and S Leskowitz. 1971. Cutaneous basophil hypersensitivity. III. Participation of the basophil in hypersensitivity to antigen-antibody complexes, delayed hypersensitivity and contact allergy. Passive transfer. J. Immunol. 107: $138-148$. 